\title{
8 Information, fairness, and efficiency in bargaining
}

\section{Colin F. Camerer and George Loewenstein}

Economic theory assumes people strive for efficient agreements that benefit all consenting parties. The frequency of mutually destructive conflicts such as strikes, litigation, and military conflict, therefore, poses an important challenge to the field.

Among economists, game theorists have devoted the most attention to inefficiency and have proposed a number of theories to explain why inefficient agreements occur. Most of these revolve around a common theme: Inefficiencies arise because parties possess incomplete information. Bargainers often lack information about how much other parties value an agreement (Babcock, 1991; Hayes, 1984; Tracy, 1987), about the personal characteristics (e.g., impatience) of the other party (Rubinstein, 1985), or the likely consequence of nonsettlement as determined by the ruling of an arbitrator or the existence of other parties willing to make a deal (Priest \& Klein, 1984).

Incomplete information impedes settlement for two reasons. First, when bargainers lack information about the other party, they may use the bargaining process to find out the missing information. For example, a union might call a strike to assess management's ability to withstand a strike. Second, when bargainers lack information about the other party's tastes or opportunities, they may overestimate the other party's willingness to make concessions. For example, the seller of a used car may hold out for an unrealistically high price in the erroneous belief that the buyer really likes the car or is impatient to buy it.

All models that explain inefficiency as a consequence of information imperfections imply that increasing the amount of information shared by the two parties will increase efficiency. Indeed, such models imply that if disputants were perfectly informed about one another's values, all agreeWe thank Maya Bar-Hillel, Jon Baron, Max Bazerman, Robin Keller, and Barbara Mellers for helpful comments NSF grant SES 90-23531 provided support to the first author. 
ments would be efficient. In this essay we challenge this prediction. We show that increasing the amount of information sometimes improves efficiency, as the game theoretic models predict, but in other situations has the opposite effect.

Shared information can interfere with settlement because people care about fairness and their view of what is fair is biased in a manner that favors themselves. ${ }^{1}$ When people lack information about the values of others, it is difficult for them to judge agreements by how fair they are. As a result, fairness cannot inhibit bargaining and create inefficiency. But when people do know how much others value an agreement, their concern for fairness - and different interpretations of what is fair based on the same information - may cause them to reject agreements, creating inefficiency.

For example, suppose two people contribute different amounts of time to a joint project. The person who worked less will typically think that equal compensation is fair, while the person who worked more will think that payments should be proportional to effort (Messick \& Sentis, 1983). If the parties bargain over how to split the proceeds from the project, and each knows how much the other worked, they may have difficulty agreeing upon a split since the one who worked more will demand a larger share of the proceeds, while the one who worked less will demand an equal share. If the parties did not know how much the other put in, however, they could not base compensation on input levels and they might be more likely to settle. In this situation, sharing information about effort can interfere with efficient settlement (precisely the opposite of the economic prediction).

We illustrate the mixed impact of information on bargaining with three experimental studies. In two of these, giving the bargainers more shared information leads to greater inefficiency, contrary to the broad game theoretic prediction. The third study shows that the effect of information on efficiency is the opposite: In a bargaining situation in which complete information is accompanied by a clear definition of a fair agreement, reducing information can create competing definitions of fairness and create inefficient disagreements.

The chapter has four sections. In the next section we describe some game theoretic models which predict that inefficiency results from incomplete information. We then present two new studies showing how incomplete information can reduce inefficiency and one showing the opposite result. Finally we discuss the results and a variety of implications.

\section{Information and efficiency in game theoretic analysis}

Game theory is a formal way of modeling social situations in which the payoffs people earn from choices are interdependent. Rasmusen (1989) is an excellent introduction.

A game consists of several players who choose strategies. The choice of 
strategies, one by each player, determines an outcome that yields payoffs to each player. In most applications of game theory to natural situations, players are assumed to care only about their own payoffs; they are not envious or altruistic, nor do they care about whether an agreement is fair (as long as it is fair enough to them). This self-interest assumption is usually made just for analytical convenience. Theorists recognize that envy, altruism, and fairness matter, but are not certain how to capture their effects in formal models. Self-interest is a kind of analytical fuel used to power the machinery of game theory (much like risk aversion in expected utility theory) Game theory is not proved false if players are fair-minded or altruistic, because the theory can run on other fuels.

Until about 20 years ago, game theorists were not sure how to model situations in which players had different information or perceptions about the choices or outcomes in a game. Harsanyi (1967-68) suggested a method that is now widely used: Assume that "nature" chooses a "type" for each player before the game begins. A player knows her own type, but others know only the distribution of probability over what her type might be. A type includes all the player's private information - the largest sum she would pay for an antique, how impatient she is, how much a strike would cost her firm each week, and so on. In a game of "complete information," a player's type is known to everyone. ${ }^{2}$ In a game of "incomplete information" (a la Harsanyi), players know only their own types. We will use the informal terms shared information and asymmetric information to refer to complete and incomplete information.

We now give examples to illustrate two situations in which inefficiency can arise when information is asymmetric.

\section{Inefficiency from strategic delay}

In the first example, Burt is thinking of buying a house from Sally. Another buyer offered \$125,000 for Sally's house; she will sell to the other buyer if a deal with Burt falls through and is therefore willing to sell to Burt at any price higher than $\$ 125,000$ - her "reservation price." Burt's reservation price is $\$ 145,000$; he will pay no more than that for the house. Since Burt's reservation price is $\$ 20,000$ above Sally's, it would be efficient for them to strike a deal: At any price $P$ between $\$ 125,000$ and $\$ 145,000$, both would prefer the deal and the sum of their gains would be $(\$ 145,000-P)+(P-\$ 125,000)$, or $\$ 20,000$.

Suppose Sally is eager to sell, so it costs her $\$ 1,000$ a week to delay the agreement with Burt. It costs Burt something to delay, too, but Sally is not sure how much: Either it costs Burt $\$ 200$ a week (if his other house is sold) or $\$ 2,000$ a week (if not). Sally guesses the two delay costs are equally likely. (The game involves asymmetric information because Sally does not know Burt's cost of delay, but Burt does.)

Suppose they bargain in the following simple way: Sally offers a price to 
Burt, who accepts or rejects it. If he rejects it, he mulls it over for a week then proposes a new price. If Sally rejects that, she proposes another price in a week, and so on. Much bargaining has this simple "alternating offer" structure.

Game theory makes the following precise prediction: Sally will offer a price of $\$ 127,000$. If Burt's cost of delay is high $(\$ 2,000 /$ week) then he will accept the price because he cannot afford to wait. If his cost of delay is low $(\$ 200)$, he will wait a week, counteroffer $\$ 125,000$, and Sally will accept it.

Notice that waiting a week is inefficient; it costs Burt $\$ 200$ and Sally $\$ 1,000$. If they could have agreed in the first week, they would have saved $\$ 1,200$ between them. But neither had an incentive to agree in the first week. If Burt's delay cost is low, waiting a week cost him $\$ 200$ but saved him $\$ 2,000$ on the price of the house. Sally figured she had a $50 \%$ chance of making $\$ 2,000$ (above her $\$ 125,000$ outside offer) if Burt settled right away, and a $50 \%$ chance of making no profit and incurring a $\$ 1,000$ delay cost if Burt waited a week. Unless she is very risk averse, she prefers to take that gamble (its expected value is $\$ 500$ ) and risk a delay. Even though both behaved rationally, the outcome of their behavior is inefficient. ${ }^{3}$

Game theory predicts that if Sally knew Burt's cost of delay, she would make an offer he would accept right away. There would be no reason for Sally to risk a delay, or for Burt to cause one because Burt could not send a message to Sally by delaying. When his delay costs are unknown, Burt's one-week delay is strategic: By waiting, he is able to show that his cost of delay is low, not high, and get a lower price.

Strategic delay is one way to convey information about how patient you are to others that you bargain with, which improves your bargaining position. ${ }^{4}$ But delay inevitably creates inefficiencies. Asymmetric information is the real culprit, because it creates a motive for strategic delay (which creates inefficiency).

\section{Inefficiency from strategic misrepresentation}

Selina owns a piece of folk art (a whittled pipe, of some value) that Byron would like to buy. Neither is sure how valuable the object is to the other.

To satisfy the modeling conventions of asymmetric information game theory, suppose Byron and Selina know what the object is worth to each of them, but neither is sure how much the other values it. Selina figures that Byron's value for the pipe is somewhere between $\$ 5$ and $\$ 100$, roughly uniformly distributed. Byron figures Selina's value is between $\$ 5$ and $\$ 100$, also uniformly distributed. Assume their values are independent.

They agree to use the following simple bargaining technique (see Chatterjee \& Samuelson, 1983): Each writes down a price, a multiple of \$5, simultaneously. If Byron's bid $B$ is less than Selina's offering price $S$ then no exchange takes place. But if $B \geq S$ the pipe changes hands at a price $(B+S) / 2$ that splits the difference between $B$ and $S$.

Suppose the pipe is actually worth $\$ 60$ to Selina. It would be foolish to 
write down a value of $S$ less than $\$ 60$ (then she might sell the pipe for less than it's worth). So she considers whether to bid $S=60$ (a truthful bid) or a value of $S$ greater than 60 (strategic mistepresentation). If Selina picks the higher price, it is less likely the pipe will be sold at all, but if it is sold she will make more profit. It turns out that Selina will maximize her expected value by strategically misrepresenting her value as long as it is below $\$ 75$; in other words, it is usually in her interest to state a price higher than her true value ${ }^{5}$ The same is true for Byron; he will strategically misrepresent his value as long as it is above $\$ 25$.

By bidding truthfully, the parties guarantee that they will always trade the pipe when they should (truthful bidding is efficient). Strategic misrepresentation introduces the inefficient possibility that they will fail to arrive at a settlement even though Byron values the pipe more highly. Bidding strategically may be inefficient, but it is more profitable in an expected value sense for both parties. As in the house-buying example of Sally and Burt, asymmetric information sometimes causes inefficiency.

\section{Inefficiencies from shared information}

These examples show how different kinds of uncertainty about what the other person gets from an agreement - their cost of delay, value, or profit - can harm efficiency in bargaining, according to game theoretic analysis. Roughly speaking, game theory predicts that bargaining should be more efficient when information is shared than when it is asymmetric.

Information may, however, have another effect that game theoretic analyses typically ignore. Lacking information about another person's values, it is difficult to tell whether outcomes are fair (since fairness involves some comparison of how much each bargainer gets). Fairness judgments are easier to make, and more likely to influence agreements, when information is shared. If disagreements about faimess reduce the efficiency of bargaining, then bargaining is likely to be more efficient when information is asymmetric (so faimess matters less), contrary to the game theoretic view.

Consider our earlier examples. When Sally sells her house to Burt, her uncertainty about Burt's delay cost makes it difficult to tell whether her initial offer is fair (since she does not know what the deal will cost Burt in the end). Sally's delay cost is $\$ 1,000 /$ week. If she knew Burt's delay cost was only $\$ 200 /$ week then the game theoretic analysis says she should offer $\$ 125,000$ initially (giving her no profit beyond the amount the other buyer had offered) (Rubinstein, 1982). We predict she would consider that offer unfair and would make a much higher offer that Burt would be likely to reject. $^{6}$

The story about Selina selling her whittled pipe to Byron suggests a different conclusion. Suppose the pipe is worth $\$ 60$ to Selina and $\$ 80$ to By. ron. Trading the pipe for $\$ 70$, splitting the difference in their values, seems extremely fair. In sufficiently simple cases, shared information may not 
harm efficiency because bargainers agree on what is fair. Instead, asymmetric information may harm efficiency by making faimess judgments more difficult or creating dispersion in what players think is fair.

Others have pointed out the subtle interactions between information, fairness, and efficiency (Foddy, 1989; Roth \& Murnighan, 1982; Roth, 1987; Smith, 1982). And of course, there are large literatures in several fields on judgments of fairness and their impact (e.g., Kahneman, Knetsch, \& Thaler, 1986; Messick \& Sentis, 1979; Yaari \& Bar-Hillel, 1984). Our main contribution is the argument - and experiments to support the claim - that asymmetric information can cut either way, improving efficiency, or reducing it depending on whether shared information causes more disputes about faimess or fewer disputes.

\section{Three experimental studies}

\section{Study 1: Appleton-Baker}

The first study is about bargaining over a plot of land. The Appletons are moving; they would like to sell a strip of land, measuring 100 feet by 200 feet, adjacent to their house. The land lies between the Appletons' house and the house owned by their neighbors, the Bakers. The land is too small for anyone else to use or build on (because of zoning restrictions in the neighborhood) and the people who bought the Appletons' house expressed little interest in buying the land. So the Appletons begin bargaining with the only sensible buyer, the Bakers.

The Appletons bought the land for $\$ 7,000$ several years earlier. Unbeknownst to the Bakers, the buyer of the Appletons' house offered $\$ 5,000$ for the land. (The $\$ 5,000$ represents the reservation price or BATNA - best alternative to a negotiated agreement - of the Appletons.)

The Appletons do not know how much the Bakers would like the land. In fact, the Bakers would love to buy the land, so they can build a new kitchen and greenhouse. The amount they would pay for the land - the Bakers' BATNA - is a treatment variable in our experiment In one condition they would pay $\$ 18,000$, in the other condition they would pay $\$ 25,000$.

Methods. Subjects were 70 Wharton MBA students in two classes on negotiations. Each subject was randomly paired with another and randomly assigned to the buyer (Baker) or seller (Appleton) role. Part of their course grade depended on how cheaply they bought the land or how high a price they sold it for. ${ }^{7}$

Students read a one-page description of their role (in a case available from the Harvard Business School) before class, and negotiated during a class period. The negotiation lasted about 20 to 40 minutes. They were allowed to bargain and exchange information (except for their BATNA values) any way they liked. 
After negotiating, students reported the prices they agreed on (if they agreed). Class discussion revealed the BATNA values and the range of prices that were agreed upon. The students were generally surprised at how low or high the other party's BATNA was. (The case is useful for teaching students to avoid overconfidence in judging the other side's BATNA.)

After the initial agreements were discussed, students were instructed to meet again with the same person and renegotiate the case in 10 to $20 \mathrm{~min}$ utes. Both the initial and renegotiated agreements counted toward their course grade.

The experimental design has two treatment variables. One treatment is distribution of information: In the initial agreement, information is asymmetric (in the game theorists' sense). In the renegotiated agreement, information is shared (because of the class discussion). The information treatment was manipulated within subjects. Notice that information is confounded with order of negotiation, but the confound is inevitable because the order cannot be reversed (after giving shared information first, information cannot be made asymmetric without changing the stimuli in some other way).

The second treatment variable, buyer BATNA (either $\$ 18,000, n=19$, or $25,000, n=16$ ) was varied between subjects.

Results. Each subject pair is a data point. Figures 1 and 2 show the two prices each pair agreed on in the two negotiations. The $Y$ axis shows the price initially agreed upon (asymmetric information) and the $X$ axis shows the price agreed upon during the renegotiation (shared information). If they failed to agree in either negotiation, the price is plotted as zero.

Consider Figure 1 first (BATNA $=\$ 18,000)$. Several effects are apparent in the graph. The initial prices are much more widely scattered $\left(s . d_{n}=\$ 3,750\right)$ than the renegotiated prices (excluding zeros) (s.d. $=\$ 1,434$ ) but the means are not different $(M=\$ 10,821$ vs. $M=\$ 10,404)$. The same effect is apparent in Figure 2 (BATNA $=25,000)$, in which the means are $\$ 13,684$ (initial) and $\$ 13,714$ (renegotiated) and the standard deviations are $\$ 4,119$ and $\$ 2,213$.

One can define three decision rules for picking a renegotiation price: Pick the equal split between the buyer and seller BATNA ("Equal Split"); pick the same price as in the initial negotiation ("Same"), or pick a price on the opposite side of the equal split ("Opposite") (as if to compensate one side for making a bad deal, relative to the equal split, initially). The three bold lines in Figures 1 and 2 show prices that pairs using each of these rules would pick. Each point is plotted as a shaded (equal split), open (opposite), or closed (same) circle depending upon which of the three lines it is closest to. Most of the points (shaded) cluster around the equal split price during the renegotiation. Slightly more pairs seem to use the oppositeprice rule (open circles, 7 pairs in total) than use the same-price rule (closed circles, 4 pairs). 
Inilial

Agreement

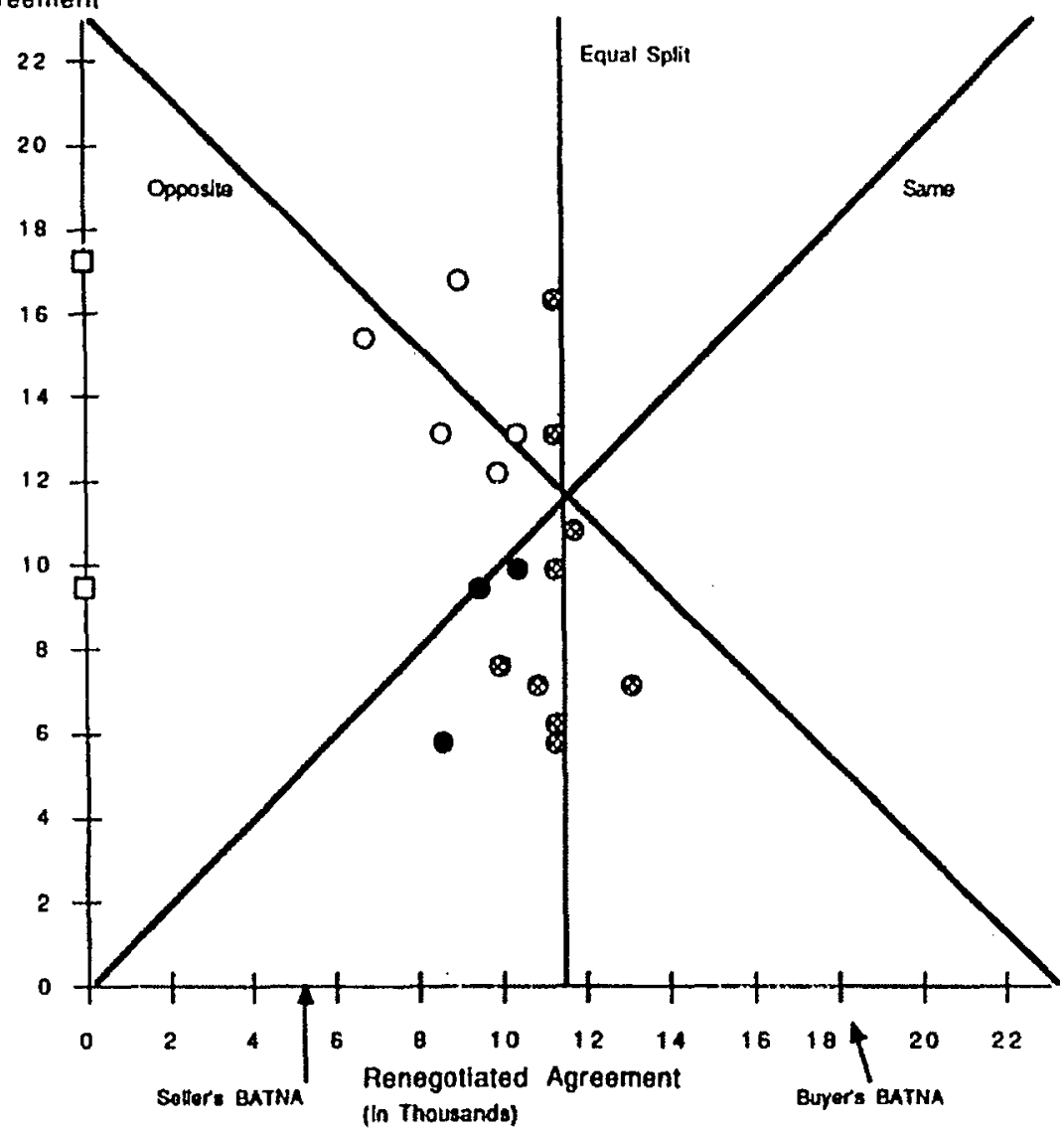

Renegutaled Agreements Closest to:

$\begin{array}{ll}\text { Equal Spit } & 0 \\ \text { Opposite } & 0 \\ \text { Szme } & \\ \text { No agrement } & \end{array}$

Figure 1 Appleton-Baker initial and renegotiated agreements (buyer's BATNA = 18)

Most strikingly, there are no disagreements during the initial bargaining (under asymmetric information) but there are 7 disagreements during the renegotiation (under shared information). The difference is small in magnitude but highly significant. ${ }^{8}$

Discussion. The subjects negotiated twice. Revealing the other side's values (BATNAs) to subjects in the second negotiation effectively transformed the 
Inilial

Agreemenl

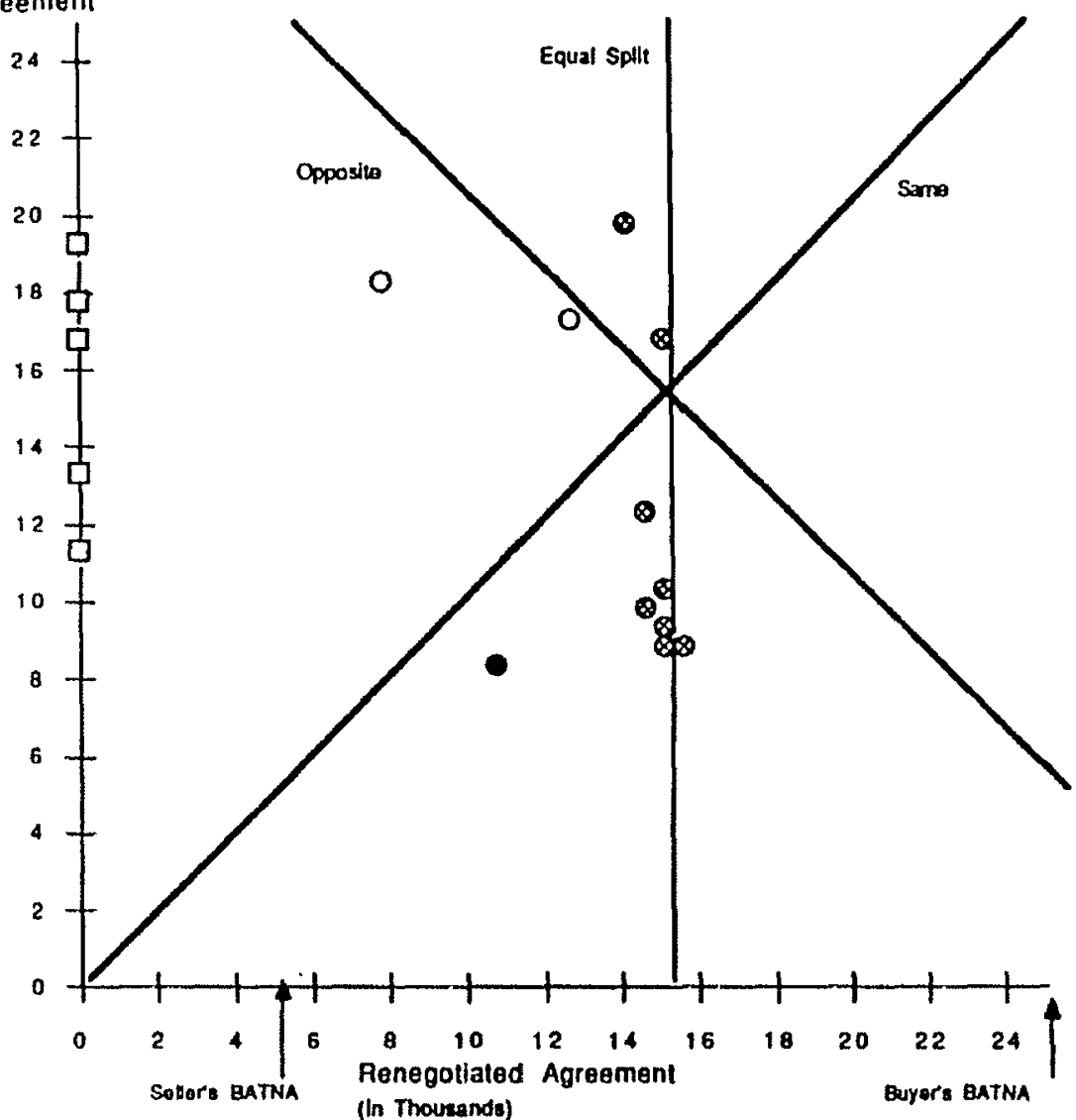

Renepotated Agreerients Closest b:

$\begin{array}{ll}\text { Equal Spllt } & 0 \\ \text { Opporito } & 0 \\ \text { Samo } & 0\end{array}$

No agreament

Figure 2 Appleton-Baker initial and renegotiated agreements (buyer's BATNA = 25).

game from one of asymmetric information to one of shared information. The average negotiated price did not change across the information conditions, but the variation in prices was roughly half as large when information was shared (excluding disagreements). The number of disagreements also rose dramatically, from none to 7 (out of 35 pairs), though disagreement was uncommon in both conditions.

Most of the disagreements happened quickly and emotionallv. A tvpical 
pattern was that one side felt it had been wronged in the initial agreement, then demanded an equal split or opposite-price settlement. When the other side disagreed, they argued briefly, angrily scrawled "disagree" on their reporting forms, and stormed off.

Our interpretation is that adding shared information caused disagreement by suggesting three fair ways to renegotiate the initial price (equal split, same-price, opposite-price). Two of these rules - the equal split and opposite-price rules - cannot be applied without shared information. Sharing information therefore gave subjects two more standards of fairness (besides equal split) to disagree about.

Our conclusions from Study 1 are speculative. We did not test whether different parties actually preferred fairness rules that benefited them (i.e., Were their assessments self-serving?). The second study fills in one of the gaps in the Appleton-Baker study by measuring fairness directly. We also tie disagreements to fairness measures and test whether the perceptions of case information are self-serving.

\section{Study 2: "Sudden impact"}

"Sudden Impact" is based on a lawsuit filed by a motorcyclist against a driver whose car hit him. The plaintiff (the motorcyclist) claimed that he sat at a light waiting to make a left turn when the car hit him from behind. The defendant (the driver) claimed that the plaintiff turned suddenly in front of him and he could not stop. The plaintiff is suing for $\$ 100,000$ in damages. The lawsuit was filed in Texas; we excerpted actual court documents and disguised some confidential details. We had a professor at the University of Texas Law School judge the case (in the excerpted form given to subjects) and decide how much he would award in damages.

Methods. Subjects were 38 graduate students from Carnegie-Mellon's School of Urban and Public Affairs and 38 law students from the University of Texas at Austin. They participated voluntarily in exchange for money.

Subjects read 27 pages of excerpled material, including depositions of key witnesses and a police accident report. ${ }^{10}$ The depositions give conflicting testimony, some supporting the plaintiff, and some supporting the defendant. After reading the material, subjects recorded how large an out-ofcourt settlement they thought was fair. They also predicted what they thought the judge would award. They earned a $\$ 1$ bonus if their guess was within $\$ 5,000$ of the judge's actual award. The actual value of the judge's award was witheld until after the negotiation ended, and was revealed only to those who failed to settle.

Each subject then attempted to negotiate a settlement with a randomly assigned partner in six 5-minute rounds. In each round, five minutes of discussion were followed by each subject writing a settlement figure on a slip of paper and exchanging them. If the plaintiff was willing to settle for 
an amount the defendant was willing to pay, the bargaining was over. If the proposed settlements did not overlap, both sides incurred $\$ 5,000$ in "legal fees" and the next round began. (Notice that every period without settlement decreases bargaining efficiency, since it incurs legal fees that reduce the sum of the plaintiff's net award and the defendant's expenses.) After six rounds, the plaintiff was awarded the judge's predetermined figure $(\$ 30,560)$.

Subjects were paid cash according to their settlements and legal fees. Plaintiffs received a dollar payment equal to the settlement they negotiated (minus any legal fees incurred) divided by 10,000 . For example, a plaintiff who got $\$ 45,000$ in the third round (incurring two rounds of legal fees, or $\$ 10,000$ ) would earn $\$ 3.50$. Defendants were given $\$ 10$ to begin with and . paid back the amount of the settlement plus legal fees, divided by 10,000.

After negotiating, each subject was given a list of eight arguments favoring the plaintiff and eight arguments favoring the defendant. Subjects were asked to "rate the importance that you think a fair judge would place on each of the arguments" using an 11-point scale.

Notice that the bargaining game has no asymmetric information (in the usual sense) because both subjects read exactly the same court documents. But we conjectured that subjects might interpret the evidence in the case in a self-serving manner, depending on their roles. We tested this by studying whether perceptions of argument importance, ratings of fair settlements, and predictions of the judge's settlement vary between plaintiff subjects and defendant subjects.

We also tested the self-serving interpretation hypothesis with a subtle treatment: In the known-role condition $(n=18)$ subjects knew whether they were plaintiffs or defendants when they read the case. In the unknown-role condition $(n=20)$ subjects did not know which role they were until after they read the case and stated what they thought was a fair settlement and the judge's likely award. (They knew their role when they negotiated, of course, and when they rated importance of arguments after negotiating.) We thought encoding of case information might be affected by knowledge of their role, leading to more self-serving interpretations, slower settlement, and inefficiency in the known-role condition.

Results. Table 1 summarizes results from bargaining pairs. First notice the substantial self-serving differences (plaintiff minus defendant) in judgments in the known-role condition: Plaintiffs thought a fair settlement was about $\$ 20,000$ more than what the defendants thought was fair, and predicted that judges would award $\$ 13,000$ more than defendants predicted. These differences are unlikely to be due to chance (they are 2-4 standard errors from zero). The differences in the unknown-role condition are not significantly different from zero, which was to be expected, since the parties did not know their roles when they assessed fairness and predicted the judge. 
Table 1 Bargaining results in Sudden Impact Study

\begin{tabular}{lll}
\hline & \multicolumn{2}{c}{ Condition } \\
\cline { 2 - 3 } Statistic & $\begin{array}{l}\text { Known role } \\
(n=18)\end{array}$ & $\begin{array}{l}\text { Unknown role } \\
(n=20)\end{array}$ \\
\hline Difference in & $\$ 20,527$ & $-\$ 4,900$ \\
fair settlement & $(\$ 5,588)$ & $(\$ 6,208)$ \\
Difference in & $\$ 12,667$ & $\$ 7,125$ \\
predicted award & $(\$ 6,461)$ & $(\$ 5,915)$ \\
Settling & $\mathbf{6 1 \%}$ & $100 \%$ \\
Mean no. of periods & 3.5 & 2.1 \\
before settlement & $(52)$ & $(.18)$ \\
Mean settlement & $\$ 35,864$ & $\$ 39,038$ \\
Difference in & $(\$ 4,025)$ & $(\$ 3,621)$ \\
importance-rating & 21.2 & $\mathbf{8 . 2}$ \\
\hline \hline
\end{tabular}

Note: Standard errors are in parentheses. All differences are plaintiff value minus defendant value. "Difference in importance ratings" is the difference in importance of proplaintiff and prodefendant arguments as rated by plaintiffs, minus the difference as rated by defendants.

Table 2 Self-serving biases and settlement in Sudden Impact Study

\begin{tabular}{lll}
\hline \hline & \multicolumn{2}{c}{ Settlement outcome } \\
\cline { 2 - 3 } Statistic & $\begin{array}{l}\text { Did not settle } \\
(n=7)\end{array}$ & $\begin{array}{l}\text { Did settle } \\
(n=31)\end{array}$ \\
\hline $\begin{array}{l}\text { Difference in } \\
\text { Gair settlement }\end{array}$ & $\$ 32,357$ & $\$ 451$ \\
Difference in & $(\$ 6,918)$ & $(\$ 4,958)$ \\
predicted award & $\$ 33,143$ & $-\$ 4,725$ \\
Difference in & $(\$ 8,416)$ & $(\$ 4,474)$ \\
importance-rating & $\mathbf{3 3 . 1}$ & 10.1 \\
\hline
\end{tabular}

The differences in fairness and predicted awards are strongly correlated with differences in bargaining behavior. Table 2 compares the differences in faimess and predicted judgment for those who settled and did not settle. For those who settled, these differences are small and not significantly different from zero. For those who failed to settle, the plaintiff's fairness figure and prediction of the judge was, on average, approximately $\$ 33,000$ more than the defendant's. The experimental manipulation also had a significant effect. All pairs in the unknown-role condition settled before the sixth period (taking about 2 periods), but only $61 \%$ of the known role pairs 
settled, taking 3.5 periods. There was no substantial difference in the average settlement amount in the two conditions.

The last row of Table 1 shows a measure of self-serving (or egocentric) bias in the ratings of argument importance made after the negotiation. The measure takes the difference in total importance ratings given by plaintiffs to proplaintiff and prodefendant arguments, and subtracts the difference given by defendants. Known-role subjects clearly rated the arguments in a more self-serving manner, even though unknown role subjects also rated the arguments nfter negotiating, knowing their role.

Discussion. In the Appleton-Baker study we did not measure fairness directly or relate it to disagreement. In the Sudden Impact study we did. Differences in perceptions of fairness strongly predicted the propensity to settle and time to settlement. Plaintiffs thought the difference in importance of proplaintiff and prodefendant arguments was greater than defendants did, and the difference in their importance ratings strongly predicted whether a bargaining pair would settle.

The data paint a picture in which incomplete information (in the game theoretic sense) is hardly a necessary ingredient for disagreement. Even when two sides receive a common pool of information, inefficient disagreements can arise if the information is rich enough and their roles encourage them to interpret the information in a self-serving manner.

The first two studies, Appleton-Baker and Sudden Impact, illustrated how adding information could increase disagreement in bargaining (and hence reduce efficiency). In both studies, more shared information created multiple notions of what outcomes were fair. Then disagreements were caused by egocentric judgments of faimess (people chose the fairness rule that benefited themselves). The third study demonstrates an opposite conclusion, which sharpens our account of how information and fairness interact to determine efficiency.

\section{Study 3: Ultimatum games}

In the ultimatum game, two people divide an amount $\mathcal{S}$. ( $S$ could represent the potential gains from a trade, like the distance between the buyer and seller's BATNAs). Their only communication is through offers. Player 1 suggests that she take $x$ and player 2 take the rest, $(5-x)$, an offer denoted $(x, S-x)$. If player 2 agrees, the bargaining is over If player 2 disagrees neither gets anything (an inefficient outcome). The game got its name because player 2's offer is a take-it-or-leave-it ultimatum.

There are several experimental studies of ultimatums under shared information (i.e., both sides know the value of $S$ ) (e.g., Thaler, 1988). People typically offer an average of $40 \%$ of $S$. Offers of $20 \%$ or less are considered insulting or unfair and often get rejected. Only 10-20\% of the offers are rejected, so efficiency is very high. 
In the ultimatum game, splitting $S$ equally is a fair offer with widespread appeal. Nearly half the offers in experiments are equal splits and they are rarely rejected. We conjectured that making the value of $S$ uncertain might increase the frequency of rejected of fers (harming efficiency), by introducing variation into what people thought was fair.

To illustrate, consider the certain case in which $S=\$ 5$ and both players know it. An offer of $\$ 2.50$ is fair; an offer of less than $\$ 1$ seems unfair. In the uncertain case, suppose $S$ is either $\$ 1, \$ 3, \$ 5, \$ 7$, or $\$ 9$ (all are equally likely). Player 1 knows the value of $S$ before making an offer, but player 2 must evaluate 1's offer without knowing $S$. Fairness in the certain ultimatum game is clear but uncertainty about $S$ creates dispersion in rules of fairness. Several rules suggest themselves; no single rule is especially appealing. One rule is to split $S$ equally. However, this rule is difficult to implement since player 2 will not be able to determine whether an offer by player 1 of, say, $\$ 1.50$ is an equal split of $\$ 3.00$ or a disadvantageous split of $\$ 7$ or $\$ 9$. Another rule is that player 1 should offer at least the minimum value of $S(\$ 1)$. However, if $S$ turns out to be $\$ 1$, player 1 is unlikely to view this as fair, since it gives her nothing. A more extreme rule is that player 1 should offer $\$ 2.50$, half of the expected value of $S$; however, this imposes a nontrivial risk that player 1 will actually have to absorb a loss if $S=\$ 1.00$.

In this situation, self-serving assessments about the fair way to deal with the uncertainty can create disagreement. In contrast, the fair thing to do in the full information condition is straightforward, at least to most subjects Thus, in this situation, we expect full information to produce more efficient outcomes than partial information.

Methods. The subjects were 46 Carnegie-Mellon University (CMU) undergraduates (66\% male) and 46 University of Pennsylvania undergraduates (70\% male) taking classes on decision making. The experiment was conducted in the two classes on the same day; it took about 15 minutes. Each CMU student was randomly, and anonymously, paired with a Penn student. Their responses were collected on one day, and money amounts were paid (in sealed envelopes) on the next day each class met.

CMU students made offers and Penn students stated the minimum offer they would accept. Note that Penn students were not told a specific offer, then asked whether they would accept it. (This method is more cumbersome to implement and gives up the opportunity to find out what is the least a person would accept). Instead, the minimum acceptable offer each Penn student stated was actually used to determine whether the specific offer by the paired CMU student would be accepted or not.

There were two treatments, certain amount and uncertain amount, which were varied between subjects. In the certain-amount treatment, CMU subjects decided how much they would offer the Penn students contingent upon a particular amount to be split (either $\$ 1, \$ 3, \$ 5, \$ 7$, or $\$ 9$ ). They were told that one of these amounts would be picked at random, and would 
count as the actual amount to be split. Penn students stated the minimum offer they would accept for each specific amount to be split. Notice that while they bargained over five different amounts, for each of the possible amounts both the CMU and Penn students knew the amount when making offers and deciding how much to accept

In the uncertain-amount treatment, CMU students also decided how much they would offer for each of the five amounts. However, Penn students stated the minimum offer they would accept, but they did not know the amount (as the CMU students did). In both conditions, CMU and Penn students completed identical forms, which made explicit to them the choice that their counterpart at the other institution would face. Forms for both conditions are included in an appendix to this chapter.

In both conditions, one of the five amounts was actually chosen for each pair of subjects. Then bargaining was carried out (by the experimenters) using the subjects' offers and minimum acceptable offers, and subjects were paid whatever they earned.

Results. Table 3 shows summary statistics for offers and minimum acceptable offers. First consider the offers by CMU students (top panel). Mean offers increased with the money amount, in a slightly curvilinear way (e.g., the offers at $S=9$ were 8.2 times as large as the $S=1$ offers, not 9 times as large). About half of the offers were equal splits. (In the two conditions, 7 and 9 subjects offered equal splits for every amount.) Fewer offers were equal splits in the uncertain-amount condition, and the standard deviation of offers was slightly larger, but those differences were not significant

Next consider the minimum acceptable offers stated by Penn students. Like CMU students' offers, these minimums increased slightly curvilinearly. The standard deviations indicate more variance in minimum acceptable offers than in offers, suggesting the application of more varied standards of fairness by player $2 \mathrm{~s}$ (Penn students).

Now compare the minimums stated in the uncertain-amount condition with those in the certain-amount condition. ${ }^{11}$ Compared to their certainamount counterparts who knew the amount was $\$ 5$, the uncertain-amount subjects demanded more on average (1.88 vs. 1.46$)$ and their demands were more dispersed (standard deviations of 1.72 vs. 1.23). Ten subjects demanded 2.50 or more in the uncertain-amount condition, compared to only two in the certain-amount condition. A Kolmogorov-Smimov nonparametric test (which is sensitive to several differences in distribution moments) indicated the two distributions of demands were only weakly significantly different (K-S statistic $=.27, p=.12$, one-tailed test).

So when they did not know the amount being bargained over, the player 2s (Penn students) generally asked for more, and their demands were more variable. Their demands also led to higher disagreement rates ${ }^{12}$ (see Table 4 ). When the amount was actually $\$ 1$, for instance, $65 \%$ of the subjects in the uncertain-amount condition demanded more than was offered, result- 
Table 3 Offers in ultimatum bargaining

\begin{tabular}{|c|c|c|c|c|c|c|}
\hline \multirow{2}{*}{$\begin{array}{l}\text { Information } \\
\text { condition }\end{array}$} & \multirow[b]{2}{*}{ Statistic } & \\
\hline & & 1 & 3 & 5 & 7 & 9 \\
\hline $\begin{array}{l}\text { Offers by CMU subjects } \\
\text { Certain amount } \\
(n=23)\end{array}$ & $\begin{array}{l}\text { mean } \\
\text { median } \\
\text { mode } \\
\text { ( } n \text { at mode) } \\
\text { std. dev. }\end{array}$ & $\begin{array}{l}.48 \\
.50 \\
.50 \\
(17) \\
.11\end{array}$ & $\begin{array}{l}1.34 \\
1.50 \\
1.50 \\
(13) \\
.38\end{array}$ & $\begin{array}{l}2.23 \\
2.50 \\
2.50 \\
(13) \\
.64\end{array}$ & $\begin{array}{l}3.12 \\
3.50 \\
3.50 \\
(12) \\
1.00\end{array}$ & $\begin{array}{l}3.91 \\
4.50 \\
4.50 \\
(12) \\
1.27\end{array}$ \\
\hline $\begin{array}{l}\text { Uncertain } \\
\text { amount }(n=23)\end{array}$ & $\begin{array}{l}\text { mean } \\
\text { median } \\
\text { mode } \\
\text { ( } n \text { at mode) } \\
\text { std. dev. }\end{array}$ & $\begin{array}{l}.42 \\
.50 \\
.50 \\
(16) \\
.17\end{array}$ & $\begin{array}{l}1.30 \\
1.50 \\
1.50 \\
(11) \\
.59\end{array}$ & $\begin{array}{l}2.21 \\
2.50 \\
2.50 \\
(11) \\
.75\end{array}$ & $\begin{array}{l}3.12 \\
3.50 \\
3.50 \\
(9) \\
1.12\end{array}$ & $\begin{array}{l}3.93 \\
4.00 \\
4.50 \\
(8) \\
1.37\end{array}$ \\
\hline $\begin{array}{l}\text { Minimum acceplable } \\
\text { offers by Penn subjects }\end{array}$ & & & & 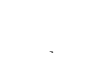 & & \\
\hline $\begin{array}{l}\text { Certain amount } \\
(n=22)\end{array}$ & $\begin{array}{l}\text { mean } \\
\text { median } \\
\text { mode } \\
\text { ( } n \text { at mode) } \\
\text { std. dev. }\end{array}$ & $\begin{array}{l}.32 \\
.38 \\
.10 \\
(6) \\
.25\end{array}$ & $\begin{array}{l}85 \\
1.00 \\
1.00 \\
(7) \\
71\end{array}$ & $\begin{array}{l}1.46 \\
1.75 \\
2.00 \\
(6) \\
1.23\end{array}$ & $\begin{array}{l}2.00 \\
2.00 \\
1.3 \\
(4) \\
1.73\end{array}$ & $\begin{array}{l}2.62 \\
3.00 \\
1,3,4 \\
(4) \\
2.26\end{array}$ \\
\hline $\begin{array}{l}\text { Uncertain } \\
\text { amount }(n=24)\end{array}$ & $\begin{array}{l}\text { mean } \\
\text { median } \\
\text { mode } \\
\text { ( } n \text { at mode) } \\
\text { std. dev. }\end{array}$ & & & $\begin{array}{l}1.88 \\
2.00 \\
0.2 .50 \\
(4) \\
1.72\end{array}$ & & \\
\hline
\end{tabular}

, Table 4 Disagreement rates in ultimatum bargaining

\begin{tabular}{lllllll} 
& \multicolumn{5}{c}{ Amount of money S } \\
\cline { 2 - 7 } $\begin{array}{l}\text { Information } \\
\text { Condition }\end{array}$ & 1 & 3 & 5 & 7 & 9 & Overall \\
\hline Certain & 11 & .15 & 14 & 15 & .17 & .15 \\
Uncertain & 65 & .57 & .35 & 23 & .17 & .39 \\
\hline
\end{tabular}

ing in inefficient disagreements. (Fourteen of 24 subjects demanded more than $\$ 1$, which CMU subjects could not offer without losing money.) Overall, $39 \%$ of the uncertain-amount bargaining ended in disagreement, more than double the $15 \%$ disagreement rate in the certain-amount condition.

Discussion. In the study of simple "ultimatum" games, when information is shared there is a single clear standard for fair outcomes. Half the offers are equal splits, and disagreements are relatively rare (15\%). Under asym- 
metric information about the amount being bargained over, offers are still centered around the equal split, but demands are now highly dispersed (reflecting competing notions of faimess created by the uncertainty), causing many more disagreements (39\%). The ultimatum results suggest that it is dispersion in assessments of faimess, not information per se, that creates disagreement. Sometimes more information creates more dispersion (in the Appleton-Baker and Sudden Impact studies) and sometimes it reduces dispersion (in the ultimatum study).

Some recent studies of ultimatum bargaining report related findings. In a design much like ours, Mitzkewitz and Nagel (1991) found no difference in efficiency in complete- and incomplete-information ultimatum games. Efficiency also rose as they repeated the game, because subjects learned to accept less and less. The difference between their results and ours could be due to differences in subjects or instructions and is worth exploring further.

In two studies (Straub and Murnighan, 1991; Croson, 1992) subjects were asked the amounts they would offer or accept if the amount being divided was known (complete information) or unknown. Subjects appear to be more fair-minded when they know how much the other person is getting, consistent with our general point that more information can increase fairness concerns (or make them calculable).

Hoffman, McCabe, Shachat, and Smith (1991) found that ultimatum offers are somewhat sensitive to details of experimental procedure (e.g., whether subjects earn the right to make the offer by winning a trivia contest). Their results can be interpreted as evidence that fairness norms are sensitive to the way in which bargaining positions are determined.

Roth \& Murnighan (1982) report results similar to ours. In their studies, pairs of players bargained over 100 chips that determined their chances of winning a dollar prize. (For example, 37 chips give a .37 chance of winning). One player's prize was $\$ 20$ and the other's prize was $\$ 5$. Notice that there are two ways to split the chips equally: Give 50 chips to each (equal chance of winning); or give 20 chips to the $\$ 20$-prize player and 80 chips to the $\$ 5$-prize player (equal expected dollar winnings).

When neither player knew the prize amounts, they agreed to divide the chips about equally; only about $10 \%$ of the pairs disagreed. When information was asymmetric, disagreement rates were much higher. For example, when the \$5-prize players knew both prize amounts, they insisted on getting 80 chips (to equalize dollar winnings) but $\$ 20$-prize players wanted 50 chips (lo equalize chances of winning); about $30 \%$ of the pairs disagreed. Thus, asymmetric information produced disagreement because players focused self-servingly on the kind of equal split that favored themselves. ${ }^{13}$

\section{Conclusions and implications}

Game theory offers the most prominent formal approach to bargaining in social science. Game theory is also increasingly popular, finding applica- 
tion in biology (Maynard Smith, 1982), economics (Kreps, 1990; Rasmusen, 1989), law (Ayres, 1990), business management (McMillan, 1992), and political science (Ordeshook, 1986).

In game theoretic analyses of bargaining, asymmetries in information can reduce efficiency in several ways. In some cases (like Burt buying Sally's house) the bargaining process is used to credibly convey asymmetric information, which inhibits achievement of the more important goal agreement. In other cases (Byron and Selina) uncertainty about the other side's values makes strategic misrepresentation of one's own information worthwhile, which risks the chance of missing opportunities to make mu* tually beneficial trades. All these inefficiencies resulting from asymmetric information should, according to the game theoretic analyses, disappear when information is shared.

Our research shows that sharing information can replace the inefficiencies that asymmetries cause with new inefficiencies. There are several ingredients in our formula for new inefficiencies. One ingredient is shared information, which is necessary for many rules of fairness to apply to proposed agreements. Another ingredient is competing fairness rules. In the Appleton-Baker study, competing rules arose because the initial negotiation in the experiment created an initial price; in the renegotiation subjects argued over whether they should choose the same price, an opposite one, or an equal split. The final ingredient is self-serving assessments of fairness (Thompson \& Loewenstein, 1991): In Appleton-Baker, those who did well in the initial agreement think that sticking to the same agreement is fair; those who did poorly want an opposite agreement or an equal split. In the Sudden Impact study, self-serving interpretations of conflicting facts in a case caused subjects to disagree on what out-of-court settlement was fair, creating inefficient delays in settlement.

Of these ingredients, our third study shows that disagreement about fairness is the most essential. In ultimatum bargaining, shared information does not cause disagreements because shared information makes an equal split of gains uniformly appealing. In that case, making information asymmetric creates variation in perceptions of fairness, raising the rate of disagreement from $15 \%$ to $39 \%$.

The notion that more information can impede settlement has significant practical ramifications because many institutions and techniques are designed to improve bargaining by promoting information exchange. Discovery rules in legal systems require opposing parties to share information. (For example, prosecutors and defense attorneys must list the witnesses they will call during a trial beforehand to enable both sides to share the information conveyed by witness testimony.) In some large firms, when one division buys a part from another, the selling division must tell the buying division how much the part costs to make. In financial markets several rules are imposed to reduce information asymmetries between investors and managers: Insider trading is prohibited, certain corporate 
data must be disclosed, and buyers must declare their motives when their ownership of a firm exceeds $5 \%$ of its shares.

The widespread belief in the beneficial effects of information is also evident in studies of mediation, which emphasizes the mediator's function as a conduit for information exchange between the parties (Kolb, 1983; Raiffa, 1982). Many of the techniques used by mediators to facilitate negotiations, such as "active listening" (Athos \& Gabarro, 1978), are intended to promote information exchange. If the central assumption that information facilitates settlement is incorrect, or correct only in specific situations, then these institutions and techniques that promote information sharing might backfire.

Our evidence implies that requiring bargainers to share information, through discovery rules and the like, may backfire because sharing information makes unfairness apparent. If parties disagree on what makes an agreement fair, they may disagree more when information is shared. We do not deny the importance of game theoretic accounts in which asymmetric information causes disagreement (for reasons unrelated to fairness). Whether information-sharing rules help, on balance, is an empirical question that depends on whether the efficiency-inhibiting effect of asymmetry or the fairness-evoking effect of shared information (which also reduces efficiency) is stronger.

Our main point is that information sharing does not automatically create perspective sharing (in fact, the opposite may occur if information is interpreted self-servingly). But when information sharing backfires, simple treatments to promote perspective sharing may work well. In the Sudden lmpact study, subjects who absorbed the facts of the case before knowing whether they were plaintiffs or defendants were much less biased in their judgments and came to settlements quicker and more often than others. The data suggest that role-playing exercises encouraging people to take the perspective of others (e.g. , Bazerman \& Neale, 1991; McMillan, 1992) could improve bargaining efficiency, especially in conjunction with sharing of information. The improved efficiency from perspective sharing also reminds us that one important service attorneys and other agents can perform is to supply objectivity when the people they represent interpret evidence self-servingly.

Our results contribute new evidence to an emerging revisionist perspective on the role of information in decision making. Economists typically assume more information is preferred to less, because information that is not beneficial can always be ignored. But some situations have been identified in which accurate information hurts those who have it or impedes economic efficiency. Smith (1982, p. 946) reports that certain experimental markets tend to converge to competitive equilibrium more rapidly when participants do not know what goods are worth to others. Camerer, Loewenstein, and Weber (1989) found that subjects who were rewarded for accurately guessing other subjects' predictions of several companies' eam- 
ings were hurt by being given information about actual earnings. In a game theory context, Brams (1980) has shown that in strategic games, if one party is omniscient (can predict the other's behavior) and both parties are aware of this, then the omniscient party can be at a disadvantage. The nonomniscient party can choose the noncooperative option, forcing the other party (who knows this) to choose a cooperative option that yields less. Information clearly plays an important role in bargaining, but whether it helps or hurts efficiency in a particular situation depends on the complex interplay of economic and psychological factors.

\section{References}

Athos, A. G. and Gabarro, J. J. (1978). Interpersonal beltavior: Communication and understanding in relationships. Englewood Cliffs, N]: Prentice-Hall.

Ayres, lan. (1990, May). Playing games with the law. Stanford Law Review, 42, 12911317.

Babcock, Linda. (1991). Impasses in contract negotiations: Why do bargainers use arbitration?, Camegie-Mellon School of Urban and Public Affairs working paper.

Babcock, Linda, Loewenstein, George, Issacharoff, Sam, \& Camerer, Colin. (in press.). Self-serving assessments of fairness and bargaining impasse. American Economic Review.

Bazerman, Max, \&x Margaret A Neale (1991). Cognition and rationality in negotiation. Oxford: Oxford University Press.

Binmore, Ken, Shaked, Avner, \& Sutton, John (1988) A further test of noncooperative bargaining theory: Reply. American Economic Review, 78, 837-839.

Bolton, Gary. (1992). A comparative model of bargaining: Theory and evidence. American Economic Review, 81, 1096-1136.

Brams, Steven. (1980, November). Mathematics and theology: Game-theoretical implications of god's omniscence. Mathemalics Mngazine.

Camerer, Colin F. (1990). Behavioral game theory. In R. M. Hogarth (Ed.), Insights in decision making: A tribute to Hillel J. Einhorn. Chicago: University of Chicago Press.

Camerer, Colin F., Loewenstein, George, \& Weber, Martin. (1989). The curse of knowledge in economic settings: An experimental analysis. Journal of Political Economy, 97, 1232-1254

Chatterjee, Kalyan, \& Samuelson, William. (1983). Bargaining under incomplete information. Operations Research, 31, 835-851.

Croson, Rachel T. A. (1992, October) Information in ultimatum games: An experimental study. Department of Economics, Harvard University working paper.

Foddy, Margaret. (1989). Information control as a bargaining tactic in social exchange. Advances in group processes (Vol. 6, pp. 139-178). Greenwich, CT: JAI Press.

Guth, Werner, \& Tietz, Reinhard. (1990, September). Ultimatum bargaining behavior: A survey and comparison of experimental results. Joumal of Economic Psychology, 11, 417-449. 
Harsanyi, John C. (1967-68). Games with incomplete information played by 'Bayesian' players. Management Science, 14: 159-182, 320-334, 486-502.

Hayes, Beth. (1984). Unions and strikes with asymmetric information, Journal of Labor Economics, 2, 57-83.

Hoffman, Elizabeth, McCabe, Kevin, Shachat, Kevin, \& Smith, Vernon I. (1991, October). Preferences, property rights and anonymity in bargaining games. University of Arizona, Department of Economics, working paper.

Kahneman, Daniel, Knetsch, Jack L.., \& Thaler, Richard H. (1986). Fairness and the assumptions of economics. Journal of Business, 59, \$285-S300.

Kolb, Deborah M. (1983). The Mediators. Cambridge, MA: MIT Press.

Kreps, David M. (1990). A Course in Microeconomic Theory. Princeton, N]: Princeton University Press.

Loewenstein, George, Issacharoff, Sam, Camerer, Colin, \& Babcock, Linda. (in press) Self-serving assessments of fairness and pretrial bargaining-Joumal of Legal Studies.

Maynard Smith, John. (1982). Evolution and the theory of games. Cambridge: Cambridga University Press.

McMillan, John. (1992) Games, strategy, and managers. Oxford: Oxford University Press.

Messick, David M., \& Keith P. Sentis. (1979). Fairness and preference. Joumal of Experimental Social Psychology, 15, 418-434.

(1983). Fairness, preference, and fairness biases. In D. M. Messick and K. S. Cook (Eds ), Equity theory: Psychological and sociological perspectives. New York: Praeger.

Mitzkewitz, Michael, \& Nagel, Rosemarie. (1991, March) Envy, greed, and anticipation in ultimatum games with incomplete information: An experimental study . Department of Economics, University of Bonn, Discussion Paper No. B-181.

Ordeshook, Peter C. (1986). Game theory and political theory. Cambridge: Cambridge University Press

Osborne, Martin J., \& Rubinstein, Ariel. (1990). Bargaining and markets. San Diego: Academic Press.

Prasnikar, Vesna, \& Roth, Alvin E (1992). Considerations of fairness and strategy: Experimental data from sequential games. Quarterly Jotirnal of Economics, 107, $865-888$.

Priest, George L.., \& Klein, Benjamin. (1984). The selection of disputes for litigation Journal of Legal Studies, 13, 1-55.

Rabin, Matthew (in press) Incorporating fairness into game theory and economics. American Economic Review.

Radner, Roy, \& Schotter, Andrew. (1989, June). The sealed-bid mechanism: An experimental study. Journal of Economic Theory, 48, 179-221.

Raiffa, H. (1982). The art and science of negotiations. Cambridge, MA: Harvard University Press.

Rapoport, A., Weg, E., \& Felsenthal, D. (1990). "Effects of fixed costs in two-person bargaining." Theory and Decision, 28, 47-71.

Rasmusen, Eric (1989). Games and information: An introduction to game theory. Oxford: Basil Blackwell.

Roth, Alvin E. (1987). Bargaining phenomena and bargaining theory. In A. E Roth 
(Ed.), Laboratory experimentation in economics: Six points of view. Cambridge: Cambridge University Press.

Roth, Alvin E., \& Keith J. Murnighan. (1982, September). The role of information in bargaining: An experimental study. Econometrica, 50, 1123-1142.

Rubinstein, Ariel, (1982). Perfect equilibrium in a bargaining model Econometricu, 50, 97-109.

(1985). A bargaining model with incomplete information about time preferences Econometrica, 53, 1151-1172.

Selten, Reinhard (1987). Equity and coalition bargaining in experimental games. In A. E. Roth (Ed.), Laborntory experimentation in economics: Six points of view. Cambridge: Cambridge University Press.

Smith, Vernon L. (1982, December). Microeconomic systems as an experimental science. American Economic Review, 72, 923-955

Straub, Paul G. \& Murnighan, Keith. (1991, October). Ultimatums, utility, minimum acceptable offers, and faimess: An experimental investigation. University of llinois at Urbana Champaign.

Thaler, Richard. (1988). Anomalies: The ultimatum game. Journal of Economic Perspectives, 2, 195-206.

Thompson, Leigh, \& Loewenstein, George (1992). Egocentric interpretations of fairness and interpersonal conflict. Organizational Bchavior and Human Decision Processes, 51, 176-197.

Tracy, Joseph (1987) "An empirical test of an asymmetric information model of strikes." Jourmal of Labor Economics, 5, 149-173

Weg, E , Rapoport, A., \& Felsenthal, D. S (1990) "Two-person bargaining behavior in fixed discounting games with infinite horizon." Games and Economic Behavior, 2, 76-95.

Yaari, Menahem, \& Bar-Hillel, Maya (1984). On dividing justly. Social Choice and Welfure, 1, 1-24

\section{Notes}

1 There have been some attempls to incorporate faimess concerns into game theoretic models (e. g. Rabin, in press). German experimentalists, most nutably Selten (1987) and Guth and Tietz (1990), have developed empirically based theories of bargaining with fairness norms as a central feature. And experimental evidence of fair-minded divisions in sequential bargaining games (Rubinslein, 1982) has provoked an important debate about fairness (e. f.. Binmore, Shaked, \& Sutton, 1988; Bolton, 1992; Prasnikar \& Rath, 1992; Thaler, 1988)

2 This is not quite true, since players might not be sure of their own types. Complete information means no single player has more information than another; everyone has the same information.

3 The Prisoner's Dilemma is the most famous example of how individual rationality can lead to collective irrationality

4 The game theory underlying the example is described by Rubinstein $(1982,1985)$ and Osbome and Rubinstein (1990, ch. 5).

5 The unique equilibrium bidding strategy is for sellers to ask max $\left(v_{s}, 25+(2 / 3) v_{s}\right)$, where $v_{s}$ is the value of the pipe to the seller, and for buyers to bid $\min \left(v_{b}, 25 / 3+(2 / 3) v_{b}\right)$ where $v_{k}$ is the value of the pipe to the buyer (Chatterjee \& Samuelson, 1983). Thus, sellers will bid their true value only if it is above 75 and will strategically misrepresent their value otherwise. Buyers will bid their true value only if it is below 25 . Radner \& Schotter (1989) report experimental tests roughly confirming that bids are a linear function of values, but report less misrepresentation of values, and thus more efficiency, than game theory predicts.

6 This prediction is consistent with findings from experimental studies of "shrinking pie 
games" in which two parties bargain over how to split a resource pool that diminishes in value if they are unable to agree. Researchers have found that, when each side's pie shrinks at a different rate, the parties take longer to settle (Raiffa, 1982, p. 52; Rapoport, Weg, \& Felsenthal, 1990; Weg, Rapoport, \& Felsenthal, 1990)

7 Although the exercise did not incorporale explicit financial incentives, the students' grades in the course depended, in part, on their performance on the exercise. Students are generally motivated to get good grades, apart from the financial ramifications; however, it is nunetheless instructive to perform a very rough calculation of the financial implications of their performance in Appleton-Baker, and thus their pecuniary incentive to obtain an advantageous price. If they do not agree, they get an exercise grade of 0 , compared to a class average of 5 That decreases their course average by .0183 (since 12 exercises are $40 \%$ of the grade, and $(-5 / 12)(4)=0183)$. Assume a standard deviation in course averages of 10 (a good approximation) and suppose a .624 average (1.24 slandard deviations above the student mean of .50 ) is required to get a grade of $A$ in the course. Studenis with averages between 6423 and .624 would be prevented from getting an $A$ by not agreeing (which reduces their average by -.0183 ); a student has a .03 chance of falling in that interval

A student with three As in four courses (the usual load) makes the "director's list" Since about $25 \%$ of the course grades are As, an average student has a $14 \%$ chance of getting exactly 2 of 3 As. Thus, a student who fails to agree has a $14 \%$ chance of needing a third A to make the director's list, and a 3\% smaller chance of not getting it because of failing to agree. Suppose making the director's list earns an incremental $\$ 1,000$ in starting salary, or around $\$ 10,000$ in discounted salary over many years. Then the financial impact of failing to agree is $(14)(.03)(\$ 10,000)$, or $\$ 42$. This amount is considerably larger than the stakes typically employed in experimental games.

8 By Fisher's exact test, null hypothesis that the disagreement rates are the same can be rejected at $p<01$ (relative frequencies are $7 / 35$ and 0/35). A within-pair test of the null hypothesis that a disagreement is equally likely in both conditions rejects the null at $p<01$ too.

9 Three experiments based on sudden impact, including the one discussed here, are reported in Babcock, Loewenstein, Issacharoff, and Cameret (in press), and in Loewenstein, Issacharoff, Camerer, and Babcock (in press).

10 The materials are available from the authors

11 The table gives only one column in the uncertain-amount condition. Subjects stated only one minimum acceptable offer because they did not know what the amount was when they stated their respective minimum offers.

12 Disagreement rates were calculated by pairing each CMU subject with every Penn subject, even though each student was only paired with one other to calculate her actual payoff.

13 However, when both players knew the prize amounts, and knew that the other player knew them too, disagreements were slightly fewer (18\%). This suggests that competing equal-split points contribute something to inefficiency (from 10\% $1018 \%$ ), and asymmetry of information contributes a little bit more (from $18 \%$ to $30 \%$ )

\section{Appendix}

\section{(Complete information condition)}

We are conducting an experiment with two undergraduate classes, one at Carnegie Mellon University and one at the University of Pennsylvania. You will be making decisions about the division of amounts of money. Penn and Carnegie students will be randomly paired with one another. Each student at Carnegie will propose a division - $\$ X$ to me, $\$ Y$ to you - to a student at Penn. If the Penn student rejects $\$ Y$, then neither student will receive any money. If the Penn student accepts $\$ Y$, then the Carnegie student will actually receive $\$ X$ and the Penn student will actually receive $\$ Y$. We will give you money in an envelope with your social security number on it after the experiment is finished (in the next class). 
Below are five money amounts. For each amount, Carnegie students will state the offer to the paired Penn students. Penn students will receive the same five amounts, but they will state the lowest offer they will accept, for each of the five amounts. Amounts must be multiples of ten cents (\$.10).

For each pair, we will randomly pick one of the five amounts, and actually pay you using that amount. If the offer by the Carnegie student is higher than (or equal to) the Penn studen's lowest acceptable offer, then the Penn student will receive the amount offered by the Carnegie student, and the Carnegie student will receive the balance. If the offer by the Carnegie student is below the Penn student's lowest acceptable offer, then both students receive nothing.

Amount Carnegie students Penn students

\begin{tabular}{|c|c|c|}
\hline$\$ 1$ & $\begin{array}{l}\text { Offer } \$ \_ \text {to me, } \\
\text { total } \$ 1\end{array}$ & Lowest acceptable offer \$ \\
\hline$\$ 3$ & $\begin{array}{l}\text { Offer } \underset{\$}{\$} \text { to me, } \\
\text { total } \text { to Penn student }_{\$ 3}\end{array}$ & Lowest acceptable offer $\$$ \\
\hline$\$ 5$ & $\begin{array}{l}\text { Offer } \$ \text { to me, } \\
\text { total } \$ 5\end{array}$ & Lowest acceptable offer $\$$ \\
\hline$\$ 7$ & $\begin{array}{l}\text { Offer } \begin{array}{l}\$ \\
\text { total }\end{array} \text { to me, } \\
\$ 7\end{array}$ & Lowest acceptable offer $\$$ \\
\hline$\$ 9$ & $\begin{array}{l}\text { Offer } \$ \_ \text {to me, } \\
\text { total } \$ 2 \text { to Penn student }\end{array}$ & Lowest acceptable offer $\$$ \\
\hline
\end{tabular}

\section{(Incomplete information condition)}

We are conducting an experiment with two undergraduate classes, one at Carnegie Mellon University and one at the University of Pennsylvania. You will be making decisions about the division of amounts of money. Penn and Carnegie students will he randomly paired with one another. Each student at Carnegie will propose a division - $\$ X$ to me, $\$ Y$ to you - to a student at Penn. If the Penn student rejects $\$ Y$, then neither student will receive any money. If the Penn student accepts $\$ Y$, then the Carnegie student will actually receive $\$ X$ and the Penn student will actually receive $\$ Y$. We will give you money in an envelope with your social security number on it after the experiment is finished (in the next class).

Below are five money amounts. For each amount, Carnegie students will state the offer to the paired Penn students. Penn students will state the lowest offer they will accept. Amounts must be multiples of ten cents (\$.10).

For each pair, we will randomly pick one of the five amounts, and actually pay you using that amount. If the offer by the Carnegie student is higher than the Penn 
student's lowest acceptable offer, then the Penn student will receive the amount offered by the Camegie student, and the Camegie student will receive the balance. If the offer by the Camegie student is below the Penn student's lowest acceplable offer, then both students receive nothing.

Penn students

Lowest acceptable offer \$

Camegie students

\begin{tabular}{|c|c|}
\hline$\$ 1$ & $\begin{array}{l}\text { Offer } \$ \_ \text {to me, } \\
\text { total } \$ 1\end{array}$ \\
\hline$\$ 3$ & $\begin{array}{l}\text { Offer } \$ \_ \text {to me, } \\
\text { total } \$ 3 \ldots \text { to Penn student }\end{array}$ \\
\hline$\$ 5$ & 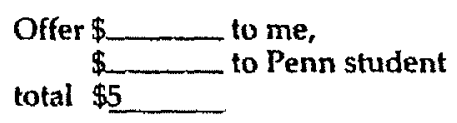 \\
\hline$\$ 7$ & $\begin{array}{c}\text { Offer } \$ \_ \text {to me, } \\
\$ \_ \text {to Penn student } \\
\text { total } \$ 2\end{array}$ \\
\hline$\$ 9$ & 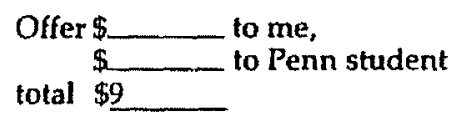 \\
\hline
\end{tabular}

